\title{
DOM DE LÍNGUAS E PROFECIA EM 1COR 14.1-40
}

Marcela de Jesus Dias*

RESUMO: 0 relato de Paulo sobre o dom de línguas e profecia de 1Cor 14.1-40, reflete os conflitos em que esses dons causavam na comunidade cristã em Corinto. Durante a estádia de Paulo na cidade portuária, nasceu uma comunidade cristã numerosa, composta por pagãos (fé cristã e cultura helênica) em geral de situação pobre e também elementos de origem judaica. A primeira Carta aos Coríntios foi escrita para orientar a comunidade especialmente por causa das divisões. Uma destas questões foi com relação àqueles que faziam uso dos dons em benefício próprio e os que usavam em prol da comunidade. 0 objetivo deste trabalho é buscar os motivos para a longa instrução de Paulo, como para o uso inadequado dos carismas de profecia e de línguas que causavam dificuldades na convivência. Para a realização do artigo é feita uma divisão em três níveis: nível histórico, literário e teológico. Os resultados residem em maior compressão dos conflitos, pelo individualismo dos coríntios. É nesse ponto que Paulo se preocupa com a edificação da comunidade nas assembleias, ele queria que os dons fossem usados para o bem de todos, sem a intensão de superioridade. Sua exortação foi para que houvesse uma ordem durante a liturgia, para que todos os presentes (convertidos ou não), fossem edificados. Por fim, este estudo fornece elementos atuais que perpassam a realidade, nas mais variadas comunidades carismáticas de hoje.

PALAVRAS-CHAVES: Carismas; Línguas, Profecia.

\section{THE GIFT OF TONGUES AND PROPHECY IN 1 COR 14.1-40}

\begin{abstract}
Paul's narrative on the gift of tongues and prophecy in 1 cor 14.1-40 demonstrates the conflicts that gifts caused within the Christian community of Corinth. During his stay in the port city, Paul witnessed the birth of a numerous Christian community composed of poor pagans (Christian faith and Hellenic culture) and people from the Jewish community. The First Letter to the people of Corinth was written to guide a divided community. One issue was related to the use of gifts to one's benefit and to the benefit of the community. Current analysis deals with Paul's instruction on the inadequate use of tongues and prophecies that was causing difficulties. The historical, literary and theological levels are discussed in current essay. Results reveal that conflicts were due to the selfishness of the people of Corinth. Paul is highly concerned with the building of the community: he wanted that gifts were used for the benefit of all, without any stance of superiority. His exhortation deals with order in the liturgy so that all present (converted or not) would be edified. The study also provides present issues within the charismatic communities of today.
\end{abstract}

KEYWORDS: Charismas; Tongues; Prophecy.

\section{INTRODUÇÃO}

As relações entre Corinto e o Apóstolo duraram praticamente uma década. Desse contato, temse conhecimento de duas epístolas que demonstram 0 tipo de relacionamento entre 0 Apóstolo e sua comunidade e 0 tipo de problemas provocados pela entra- da de muitos pagãos na igreja. Mas é graças a essas cartas que se reconstitui até certo ponto os problemas da missão no mundo grego e a maneira como Paulo abordou e resolveu esses problemas. Paulo formou uma comunidade cristã, que aderiu a pregação do evangelho de Cristo com a ajuda dos colaboradores (Crispo, Erasto, Estéfanas, Febe, Caio, Aquila, Pricila). 
Fundada depois do ano 49, após o "conflito de Antioquia" (Gl 2.11-15) é o momento em que 0 apóstolo empreende seu caminho missionário para Europa, acompanhado por Silas (At 15.40), e imediatamente unido a Timóteo (At 16.3). Atravessam a Ásia menor, navegam até a Europa, evangelizam a Macedônia (Filipos, Tessalônica e Bereia), e também Atenas (At 17.15). Dali, 0 apóstolo dos gentios envia seus colaboradores em visita à comunidade de Tessalônica e Filipos (1Ts 3.1s; At 18.5), enquanto deixa Atenas e passa em Corinto (At 18.1).

Em Corinto, durante a estadia de Paulo nasceu uma comunidade cristã numerosa, composta, sobretudo, por pagãos (fé cristã e cultura helênica) em geral de situação pobre (1Cor 1.26-29; 12.2). Havia também elementos de origem judaica (At 18.8; 1Cor 1.22-24; 10.32; 12.13). 0 perigo era que o povo por influência da cultura pagã, fosse capaz de capturar a mensagem evangélica e enredá-la nas próprias ideologias.

Paulo não retorna mais para a comunidade em Corinto. É sua carta que vai guiar na reconstrução da ligação que o apóstolo manteve com a comunidade. Essa ausência de Paulo gera vários conflitos e situações em Corinto. Ainda mais por ser formada de cristãos de várias procedências, a comunidade tinha grande dificuldade para realizar efetivamente a comunhão de vida. Havia conflitos e divisões: entre judeus e gregos (1Cor 12.13): uns queriam milagres, outros a sabedoria (1Cor 1.18-31); escravos e livres (1Cor 7.21-23; 12.13); homens e mulheres (1Cor 7; 11. $3-15$; 14.34-35); ricos e pobres (1Cor 11.22); partidários de Paulo, de Cefas e de Apolo (1Cor 1-4); os que queriam apossar-se dos carismas em proveito próprio e os que usavam para edificação da comunidade (1Cor 12-14); partidários de conduta totalmente permissiva e os que tinham medo de enfrentar o mundo (1Cor 8-10), (CARREZ, P. 75-76).

Nas questões teológicas, éticas e sociais haviam tensões (SCHNELLE, P. 240) pouco contempladas nos comentários das cartas, pelo menos enquanto fatores que incidiram diretamente na doutrina e nas orientações à boa conduta da comunidade. A primeira Carta aos Coríntios foi escrita para orientar a comu- nidade especialmente por causa das divisões (1Cor 1.10-11). Uma destas questões foi com relação àqueles que faziam uso dos carismas em benefício próprio e os que usavam em prol da comunidade, como 0 uso inadequado de profecia e de línguas (1Cor 14.4).

A questão carece de aprofundamento em vista de compreender a insistência de Paulo na unidade e comunhão dos cristãos. Ademais uma análise sócio-literária da carta revela a situação conflituosa, 0 método empregado por Paulo na sua parênese e a estatura teológica deste grande apóstolo em sua atuação e legado. 0 estudo dos problemas da comunidade poderá ajudar a discernir nos seus escritos aos coríntios a identidade desta comunidade cristã, como afirma Campbeel (p. 271): "Em solidariedade com Cristo, os cristãos formam um só corpo, uma só família da qual todos fazem parte".

\section{METODOLOGIA}

0 método aplicado para a realização da pesquisa foi uma divisão em três níveis: nível histórico, literário e teológico. No nível histórico foi estudado 0 autor, tempo de composição e a comunidade cristã em Corinto. Aqui se recorreu aos manuais de história do mundo grego, do império romano e sua influência na organização da sociedade. Foram utilizados alguns materiais que fazem uma introdução às cartas paulinas e da história do cristianismo nos primeiros séculos. Esses dados são importantes para reconstruir o retrato da comunidade. 0 texto foi analisado como um produto histórico social que abrange o lado social, político e cultural-ideológico. Foi conferido cada dado do texto junto aos seus conflitos.

No nível literário foi usado o método histórico-crítico em que pôr primeiro houve a delimitação do texto do bloco literário de 1Cor 12-14; foi notada a estrutura do texto; os elementos de unidade; a língua do texto escrito. Na análise do texto foi possível ver as palavras-chaves mais repetidas, os verbos, os sujeitos desses verbos.

0 terceiro nível é o teológico em que a hermenêutica feita é trazida para uma atualização da época 
presente. Vence a distância do tempo em que 0 texto foi escrito e a nossa época.

\subsection{ANÁLISE DE 1COR 14.1-40}

Nesse estudo será realizada uma análise mais criteriosa de 1Cor 14.1-40. Há necessidade de uma contextualização dos carismas na cidade de Corinto, na sua cultura, religião e nos costumes da época. Haviam divisões sérias na comunidade (1Cor 1-2). Existia também disputas em relação aos carismas, cada um queria se sobressair sobre os outros. Causavam problemas na comunidade de Corinto especialmente em relação aos carismas de profecia e línguas. Paulo trata longamente desses carismas em 1Cor 14.

Em sua dimensão histórica, literária e teológica. Do ponto de vista histórico com estudo da realidade sociocultural de Corinto. 0 método histórico-crítico supõe responder a questões como a). quando o texto foi escrito? b). quais os destinatários da carta? c). qual a situação da comunidade onde 0 texto foi escrito? d). quais os objetivos da instrução de Paulo? Da perspectiva literária com uma análise dos carismas e sua função em 1Co 14. Para isso, será ponderoso entender 0 texto no bloco literário de 1Co12-14, para compreender o significado do dom de línguas e profecia na comunidade cristã. A análise literária do estilo, a análise da composição do texto para averiguar sua unidade em torno de um tema central e análise de estrutura do relato, são elementos necessários para a interpretação do texto e o significado teológico dos carismas em questão.

\section{RESULTADOS}

Paulo em sua carta está tratando de questões práticas para a melhor comunhão de vida da comunidade que fundou em Corinto. Sendo interrogado sobre os carismas, o apóstolo explica aos cristãos da comunidade em Corinto a fonte e a razão de ser dos carismas (1 Cor 12) e as regras práticas para 0 uso dos carismas e a sua hierarquia (1Cor 14), onde se verifica claramente a repetição do verbo edificar por sete vezes. Os carismas têm como função unir (1 Cor 12. 1230) e edificar (1 Cor 14. 3,4,5,12,17,28) a comunidade. Com isso, em contraposição ao mundo pagão, Paulo não quer deixar os seus na ignorância (1 Cor 12.1-2) buscando purificar os impulsos recebidos pelas religiões dos gentios.

Os dons espirituais, que no vocabulário Paulino (grego: $\mu$ ) substantivo neutro: carisma indica que expressa 0 resultado do ato de dar graciosamente. Por definição, segundo Dunn (2003, p. 625), "carisma é o resultado de ato gracioso de Deus; é a graça divina concretizada e expressa em palavra ou ação". Em Paulo, pode-se indicar todos os favores recebidos de Deus, tendo seu uso mais comum em referência a carisma para a assembleia. Desta forma, ele não considera condições reservadas somente a manifestações extraordinárias como se podia verificar nos cultos pagãos em Corinto, ou no poder de operar milagres no seio da comunidade, mas compreende também os carismas como função de assistir o próximo na caridade (1Cor 12.28), por isso são diversos os dons espirituais.

Nesta primeira carta que Paulo direciona aos coríntios pode-se constatar um bloco literário dos capítulos 12-14, os três capítulos se correlacionam em seus conteúdos. No capítulo 12, encontra-se uma das principais listas dos carismas identificadas nas cartas de Paulo, também há uma teologia do corpo evidenciando a unidade dos membros da comunidade. Ao longo deste capítulo há uma sequência de repetições das palavras: dons (04 vezes); dom (05 vezes); Espírito (09 vezes); corpo (18 vezes). Palavras estas que são chave para o bom entendimento da perícope. Devido às divisões que estavam acontecendo em Corinto, 0 apóstolo teve que intervir colocando a imagem do corpo com seus membros para que a comunidade refletisse de maneira que pudessem entender que não existe um corpo que seja composto de apenas um membro, mas de muitos (1 Cor 12.12-26). Paulo relata a importância de até o membro mais fraco ser necessário no corpo, atualizando este exemplo para declarar que a comunidade cristã é o corpo de Cristo e os seus membros, cada um com seus dons para a união e edificação de 
todos. No capítulo 13, Paulo coloca como central 0 tema da caridade (no meio dos capítulos 12 e 14), para evidenciar 0 que deve ser considerado critério máximo na análise dos carismas tratados neste bloco. Por mais estranho que pareça em tratar de Agape neste bloco, que não é propriamente um carisma, nem apresentado como um; este trecho ao analisar tem ligação com 0 capítulo antecedente e o posterior:

parece pois, uma digressão fora de lugar. Por outro lado, no início do cap. 14 a exortação: "Aspirem aos dons do Espírito" parece retomar a exortação de 12,31a: "Aspirem aos melhores carismas". 0 nosso capítulo, introduzido por $12,31 \mathrm{~b}$ - "E mais: quero mostrar-Ihes a via por excelência" - e concluído por 14,1a - "Procurem o amor" -, pode parecer um parêntese. A propósito de 12,31, a ligação do tema do amor com 0 dos carismas. Com maior clareza, ainda, essa conexão aparece no cap. 13, no qual é característico o confronto entre amor e dons do Espírito (BARBAGLIO, 1989, p. 332).

Em último capítulo deste bloco, o carisma profecia da qual trata a epístola ao longo do capítulo 14 , verifica-se que tem o poder de edificar, exortar e consolar. É um texto pastoral em que Paulo se apoia no discernimento dos espíritos que completa e leva à perfeição, como 0 dom de interpretação com relação ao dom de línguas, à glossolalia. Paulo orienta no v.26 "Que tudo se faça para a edificação", os dons, segundo a orientação do Apóstolo, têm sua importância em edificar a todos

quem fala em línguas e recebeu a oportunidade de louvar a Deus na língua dos anjos, deve pedir para que possa interpretá-lo para a comunidade, pois somente isto serve à edificação da comunidade (1Cor 14.4,5). A glossolalia como um carisma aparentemente muito estimado em Corinto e restrito a esta comunidade não foi rejeitada por Paulo, mas vinculado ao objetivo crítico da $\mu$, de modo que já não pode ser um instrumento da auto apresentação individualista.
Quando se traduz a glossolalia, ela ganha o mesmo significado que a profecia: ela fortalece 0 irmão na fé (1Cor 14.16-17), serve à comunidade e aos cristãos individuais (SCHENELLE, 2010, p.273).

Os últimos dons que Paulo vai tratar de sua lista no capítulo 12 é 0 dom de falar em línguas e 0 dom de interpretar. Na comunidade de Corinto havia predileção exagerada por esses dons, pois eram considerados dons especificamente sobrenaturais. À primeira vista nos parece que Paulo coloca esses dons "no final da fila", pois na distribuição dos dons não pode haver desigualdade. Possivelmente, os dons sobrenaturais na comunidade de Corinto traziam alguma posição social elevada dentro da comunidade.

Por isso Paulo, vai dizer que tudo é obra de um único e mesmo Espírito, distribuindo os dons como the apraz (1 Cor 12.11). Este versículo coloca em relevo a ação e a soberania do Espírito Santo que distribui os carismas de maneira livre, sem predileção. Sendo assim, aquele que receberia um dom não deve ansiar outros dons, e aqueles que fora agraciado por um dom "mais elevado" não deveria diminuir outro fiel do corpo da comunidade. Todos os carismas deveriam concorrer para o bem da comunidade. Desta forma, os versículos que seguem (vv. 12-13) atestam que Paulo, diante da concretude de uma comunidade com divisões por causa dos carismas recebidos por Deus, se faz necessário 0 apelo à unidade e a solicitude fraterna que os membros devem ter uns com os outros, não só para o interno da comunidade, mas como instrumento de abertura para a igreja universal, "onde judeus e gregos, escravos e livres, todos bebem do mesmo Espírito para formar um só corpo".

Com essa visão ampla em relação a esse bloco literário, pode-se delimitar o texto de 1 Co 14, qual foi redigido nos anos 54/55. Neste capítulo, Paulo volta sua atenção para as reuniões da comunidade, enquanto lugar de atividade dos carismáticos. Nota-se também a relação entre manifestações do Espírito e 0 crescimento da comunidade cristã. 0 texto trata os carismas atuando no interior das assembleias eclesiais 
por meio do Espírito. E com maior precisão, o texto dá bastante atenção ao confronto entre carisma, profecia e glossolalia, demonstrando a intenção de deixar clara a superioridade da primeira em relação à segunda. Mais que dois carismas, observam-se dois dons do Espírito: um, que é de utilidade para o culto em comunidade e outro que edifica só o interessado de modo particular. Evidencia-se neste capítulo a intenção crítica em relação ao individualismo dos carismáticos em Corinto. Não deixando de reparar numa continuidade aos capítulos anteriores, complementando em seu conteúdo.

Neste texto há uma articulação de duas partes no capítulo,

a primeira parte (vv. 1-25) está concentrada no confronto entre profecia e glossolalia, instituído sob a marca da repetida afirmação da superioridade daquela sobre esta. A concreta regulamentação das intervenções dos carismáticos nas reuniões comunitárias especifica a segunda parte (vv. 26-36). 0 capítulo termina salientando dois pontos: o primeiro é uma firme reinvindicação, da parte de Paulo, da autoridade de sua intervenção (vv. 36-38); o segundo é o resumo de seu longo discurso (vv. 39-40) (BARBAGLI0, 1989, v.1, p. 341)

Neste capítulo há dois casos particulares 0 da glossolalia e 0 da profecia (a palavra "profecia" aparece 14 vezes e 15 vezes a palavra "língua"), esses dons provocam sérias dificuldades nas assembleias da comunidade. Antes de uma análise do texto, é necessário deixar evidente 0 que se entende por profecia $\mathrm{e}$ glossolalia.

\subsection{PROFECIA}

No capítulo do estudo, pode-se entender a figura do profeta.

1. Segundo o v.3, o profeta é aquele que diz uma palavra com destinatário a alguém, palavra essa comunicativa e compreensível que "edifica, exorta e consola". É, pois, um apelo à vontade do ouvinte, para que ele seja responsável e, ao mesmo tempo para sustentá-lo nas suas dificuldades e nos momentos de instabilidade, ou seja, de crise.

2. No v.16 a palavra profética pode ser concebida pelos presentes, que desse modo podem participar dela com uma resposta 0 "Amém".

3. Em vv.24-25 o profeta tem a capacidade de revelar o que se oculta no mais íntimo daqueles que ouvem, revelando os segredos do coração. Também é a força capaz de contestar suas vidas, chamando-0s à conversão. Ele revela as exigências da vontade de Deus para a realidade das situações humanas, e isso o faz prontamente, pois é inspirado por Deus (v.30).

4. Outra função da palavra profética está no v. 31, é a instrução da qual todos aqueles quem possuem 0 dom de profecia aproveitam.

Por fim, será profética toda a palavra inteligível de instrução, de exortação e de encorajamento dos fiéis.

\subsection{GLOSSOLALIA}

Paulo situa 0 dom de línguas entre os dons externos que manifestam a presença e a ação do Espírito Santo (1Co 12:1-11).

A palavra glossolalia, no texto grego, denomina-se literalmente língua (glôssa), línguas (glôssai). Em 1Co 14 podemos ter uma noção desse dom.

5. No v. 2, Paulo situa este fenômeno em nível de espírito, pois em espírito enuncia coisas misteriosas, ou seja, fala mistérios a Deus e não as pessoas.

6. Os vv. 10-11 compara-se a glossolalia a uma linguagem desconhecida, no capítulo 13:1 e 2Co 12:4 fazem referências há hipótese de uma linguagem celeste e angélica. 
7. A glossolalia nos vv.14-16 consiste em falar e orar de modo incompreensível (oração espiritual e oral, mas não mental), "salmodiar no espírito", "dar graças". Este "falar em línguas" é uma maneira de "falar a Deus", isto é de orar (SULLIVAN, 1983, p.122-131).

8. Trata-se no v.19 de uma linguagem no sentido que este "falar" tem certa semeIhança com a linguagem humana articulada; 0 apóstolo de fato usa a expressão: "dizer dez mil palavras em línguas".

9. Não é, porém, uma linguagem reconhecível, uma língua estrangeira: no v.23 PauIo não dá a entender que um estrangeiro pudesse entender; é uma linguagem que ninguém compreende, nem mesmo aquele que fala (v.16). Também neste versículo explica a impressão de loucura, pois todos falavam juntos e pronunciavam frases incompreensíveis.

0 dom de falar em línguas era um fato $\mathrm{co}_{-}$ mum nas reuniões da comunidade em Corinto. Todo 0 discurso de Paulo, e especialmente as regras dadas, pressupõe que a glossolalia não seja um fenômeno de êxtase, mas uma atividade na qual a pessoa não perde 0 domínio de si, nem a razão. Barbaglio (1989, v.1, p.342) afirma que esse fenômeno "trata-se de uma experiência transracional, caracterizada por explosões verbais emotivas, enigmáticas, carregadas de "phatos", mas absolutamente ininteligíveis". Ou seja, é uma linguagem incompreensível por quem fala e por quem ouve, feita em espírito. Mas que pode ser dominada pelo falante. Os estudiosos da questão afirmam que a êxtase é um estado psicológico no qual a faculdade da presença mental aos dados reais da experiência comum se encontra suspensa, até mesmo a faculdade de autocontrole da própria atividade. (SCIPPA 1982, p.44200), interpreta a glossolalia como êxtase, na qual se servindo somente do pneuma deixa de lado a faculdade da inteligência (nous). Porém (SULLIVAN 1983, p. 122-131), observa que a distinção entre pneuma e nous, não podem ser colocados sob o plano da êxtase. (VANHOYE 1990, p. 98) segue a posição de Sullivan e considera este argumento contestável. Compreendese que os coríntios a privilegiassem como notória expressão da inspiração divina e da entrada do ser humano no mundo espiritual, divino.

Paulo, ao escrever 1Cor 14, dá início a este capítulo retomando 0 assunto do conteúdo precedente, exortando a procurar 0 amor. 0 dom por excelência que ele exalta é a caridade. De nada vale 0 dom de línguas ou da profecia, se não tiver a caridade (1Cor 13.1-13). Após fazer essa ligação, introduz o nosso tema: "Aspirai aos dons do Espírito, principalmente à profecia". A partir do v.2 0 apóstolo explicará o porquê almejar 0 dom de profecia e deixa clara a sua preferência por esse dom e sua tese de superioridade do dom de profecia em relação ao dom de línguas (dom este que os coríntios privilegiavam).

Em seguida, Paulo exemplifica nos vv.7-9 e vv.10-12 com duas comparações: dos instrumentos musicais e da língua estrangeira para dar suporte a sua tese. Paulo de fato evidencia as características dos dois carismas como antitéticas, a sua preferência pela profecia, qual é superior à glossolalia, coloca uma reserva para este dom que ele caracteriza como inferior, a glossolalia só tem importância para ele se for acompanhado pelo dom de interpretação. A questão é que Paulo está preocupado com a edificação da comunidade (v.12), já os coríntios estão interessados em edificarem a si mesmos. 0 escritor vai dando sequência com os vv.13-17 que relata o confronto entre glossolalia e profecia no campo da oração: orar em espírito e em inteligência.

Nos vv.18-19 há um acréscimo por Paulo pela sua preferência em falar de maneira inteligível, ele argumenta usando sua própria pessoa "Dou graças a Deus por falar em línguas mais que todos vós" esse repetido discurso por falar de modo inteligível não só vale para os coríntios, mas para ele também. Com efeito afirma: "Mas, numa assembleia prefiro dizer cinco palavras com minha inteligência, para instruir também os outros, a dizer dez mil palavras em línguas" (v.19). 0 bem da comunidade, a utilidade da 
igreja vale mais que 0 individualismo. Em vv. 20-21, é feita uma exortação, por privilegiarem os carismas extáticos, Paulo compara como a uma atitude infantil, em que é necessário amadurecer no entendimento. Logo é seguido de uma citação do antigo testamento. É difícil fazer uma conexão com os vv.22-25 que são posteriores, quais vão adentrar uma afirmação que 0 falar em línguas é sinal não para os que creem, a profecia 0 é para os fiéis.

Resolvida a primeira parte desta perícope acerca do confronto entre profecia e glossolalia, 0 apóstolo passa agora para as regras práticas em relação aos carismáticos nos vv. 26-33a, a sua intenção precisa se revelar nestes versículos, v.26: "Quando reunidos, cada de vós pode cantar um cântico, proferir um ensinamento ou uma revelação, falar em línguas ou interpretá-las, mas que tudo se faça para a edificação". É na última parte do versículo em que o problema vem implícito com 0 imperativo: "tudo se faça para a edificação", em que cada um deveria dar a sua contribuição, 0 espírito se manifesta em cada um para a serventia de toda a comunidade e 0 crescimento desta. Só que Paulo observa que cada membro da comunidade apresentava a própria capacidade, criando um clima de competição e concorrência: "eu tenho um Salmo inspirado "diz um; "eu tenho uma revelação" diz outro; "eu possuo o dom de línguas "diz outro. E assim por diante.... Tal competição colocava em perigo a ordem na assembleia, a afinidade no relacionamento entre os cristãos, a capacidade construtiva da comunidade, procedendo desta forma favorecia por outro lado a confusão, os atritos e conflitos. Barbaglio (1989, v.1, p.347) menciona "Mas para que a riqueza das intervenções não se torne fator de confusão caótica, que impediria a eficácia da palavra proclamada e ouvida, impõe-se a exigência de limitações práticas". Limitar as intervenções se dão nos vv.27-32 tanto para os glossalos quanto para os profetas e seguido do v.33 qual Paulo declara que "Deus não é Deus de desordem, mas de paz", por isso ele faz essas intervenções nas reuniões dos coríntios.

Seguem-se os vv.33b-36, quais estão ausentes a problemática, própria do capítulo, do con- fronto entre glossolalia e profecia, tratando o comportamento das mulheres nas assembleias.

Concluindo, nos vv.37-38, 0 apóstolo menciona que tudo que foi prescrito por ele deve ser reconhecido como um preceito do senhor Jesus. E só aqueles que forem espirituais, verdadeiramente inspirados pelo Espírito Santo podem reconhecer o Senhor. Quem 0 rejeitar será também rejeitado por Deus, ou seja, todo aquele que rejeitar esse preceito é alcançado pelo juízo divino de condenação. Em v.39, Paulo resume tudo 0 que foi desenvolvido por ele no capítulo: exortação a se preferir o dom de profecia; não impedindo ninguém de falar em línguas.

\section{DISCUSSÃO}

Após desenvolver este trabalho com seus resultados em relação a 1Cor 14.1-40, constata-se nesta pesquisa a necessidade de uma atualização acerca da reflexão de Paulo sobre os carismas para a realidade presente. Realidade essa que tem fatores parecidos com a comunidade de Corinto, mesmo que se passado quase 2 mil anos de quando a carta foi escrita pelo apóstolo.

Esse tema é bem atual no movimento pentecostal, neopentecostal e na renovação carismática católica. Sendo assim, essa manifestação de dons nem sempre foi compreendida por esses movimentos em suas raízes bíblicas. Ao tratar Paulo longamente em 1Co 14, percebe-se que sua preocupação era com a edificação da comunidade, se estavam sendo edificados pelo que acontecia durante as assembleias dos coríntios. Para que todos aqueles que fossem convertidos ouvissem palavras que "edificam, exortam e consolam" e aqueles que não fossem, ouvissem palavras que confrontasse seu estado de vida, revelando os segredos do coração, levando-os à conversão. É disso que as comunidades eclesiais de hoje precisam, que todos aqueles que adentrarem pelas portas da igreja, tanto convertidos como não venham a ser edificados pela palavra inspirada pelo Espírito Santo. E onde 0 Espírito Santo se faz presente, esse se manifesta de 
forma inteligente, atuando nos corações do ouvinte e levando-0s ao arrependimento.

Nos movimentos citados, tem em seus participantes a presença de dons operantes nos cultos e missas, principalmente 0 de falar em línguas qual Paulo tanto ensina aos coríntios de como tinham que proceder em relação à glossolalia. 0 indivíduo qual possui este dom, que faça uso deste para sua edificação própria, para falar a Deus. Mas que não seja como ocorria em Corinto, uma desordem a ponto de quem chegasse na comunidade achava que estava em estado de loucura; outro problema é que os coríntios ao ouvirem a recomendação de Paulo em "aspirai pelos dons do Espírito" (v.1), para eles o dom de importância é 0 de línguas, já para 0 apóstolo é o da profecia. Isso se faz presente no meio dos pentecostais e neopentecostais, em que alguns consideram de forma errada 0 entendimento de ser cheio do Espírito Santo com ter 0 dom de línguas, trazendo certa superioridade para com aquele que não possui este dom.

Na renovação carismática católica, Carranza (2000, p.24) descreve bem alguns desses elementos comportamentais típicos dos carismáticos e detectáveis ao primeiro olhar,

rezar de braços elevados para 0 alto; [...] a emotividade, a afetividade e a espontaneidade atuando como meios de comunicação; a referência constante de sensações como indicativas de experiências místicas e a certeza da presença de Deus; a necessidade de milagres como prova da existência divina e, finalmente, o batismo no Espírito Santo, manifestação que confere especificidade ao Movimento dentro da Igreja Católica.

Com todas estas características ainda não podemos concluir que essa pessoa está cheia do Espírito Santo. Pois estar cheio do Espírito Santo é entender que todo aquele que confessa Cristo, passa a ser um cristão, sendo assim a "ser templo de Deus" (1Co 3.16), é não estar na carne, mas no espírito; é a habitação do Espírito Santo e recebe seus dons, é situar o espírito na parte superior, intelectual e moral do homem.

Por fim, pode-se confirmar que a intervenção de Paulo na comunidade de Corinto em relação aos carismas foi para que houvesse uma ordem na liturgia em 1Co 14, esse relato ainda se faz atual e perpassa a realidade de hoje. Por desfecho deste trabalho é possível notar certas dificuldades na atualização destes carismas, em entender como acontecem na prática nas mais variadas comunidades de hoje, a saber se é ação do Espírito Santo ou não. Para isso é necessária uma pesquisa mais profunda em relação às comunidades que dizem ser carismáticas. Com uma teologia em cima desses movimentos, em relação a todos os indivíduos que bebem da fonte do espírito.

\section{CONCLUSÃO}

A base para a existência cristã é a participação do Espírito Santo; viver em Cristo e ser justificado pelo dom de Deus. Esta é a síntese do pensamento apostólico. Paulo no bloco literário de 1Cor 12-14 deixa bem clara a participação do Espírito Santo, na distribuição dos dons, na caridade e nos carismas atuantes na liturgia. Este trabalho se deteve em alcançar os objetivos que nortearam esta pesquisa, seu itinerário se propôs a compreender 0 direcionamento qual Paulo ousou a exortar a comunidade de Corinto em relação à ordem no culto, tratando dos carismas de línguas e profecia.

É interessante 0 contexto onde Paulo está inserido, na comunidade de Corinto qual ele fundou era numerosa, composta sobretudo por pagãos (fé cristã e cultura helênica) em geral de situação pobre, havia também elementos de origem judaica. Em relação à convivência, o apóstolo apresenta a primeira carta aos coríntios que foi escrita para orientar a comunidade por causa das divisões. Uma destas questões foi com relação àqueles que faziam uso dos carismas em benefício próprio e os que usavam em prol da comunidade, como 0 uso inadequado de profecia e de línguas (1Cor 14.4). Paulo se preocupava na edificação da comuni- 
dade nas assembleias, ele queria que os dons fossem usados para o bem comum, sem ter em cada indivíduo a intensão de superioridade para com 0 outro. Para isso buscaram-se os fundamentos teológicos para os carismas e evidenciaram-se as exortações de Paulo, na utilidade dos carismas com a intensão de edificar a comunidade com o dom de profecia e línguas junto a um dom complementar - 0 da interpretação. A longa exortação de Paulo tem todo um sentido,

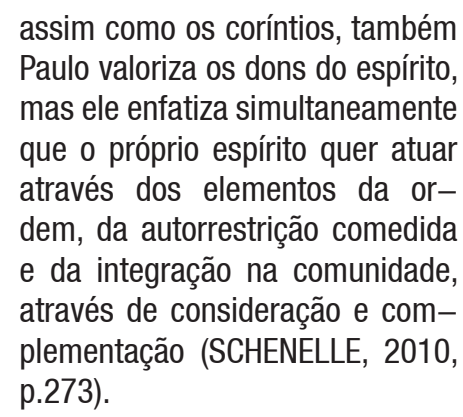

A atuação dos dons na comunidade pelos carismáticos, só tem sentido quando partilhados. Sem essa partilha tem-se 0 risco de cair em um individualismo. Por isso Paulo orienta os seus, enfatizando a importância do bem comum. 0 espírito manifesta-se de várias maneiras, mas é sempre o mesmo que atua em todos sendo este não um divisor, mas unificador. Segundo Schenelle (2010, p.273), o espírito "conduz à riqueza da diversidade, mas não a pobreza da fragmentação".

Por fim, os resultados alcançados residiram numa maior compreensão dos conflitos em Corinto em relação ao dom de línguas e profecia apontados por Paulo. Portanto, conclui-se que o estudo da primeira epístola aos coríntios, em especial a perícope de 1Cor 14.1-40, fornecem elementos atuais que perpassam a realidade presente. Apesar de certas dificuldades na atualização desses carismas, em entender como acontecem na prática, nas mais diversas comunidades eclesiais carismáticas de hoje.

\section{REFERÊNCIAS}

BARBAGLIO, G. As cartas de Paulo (I). São Paulo: Paulinas, 1989.

BÍBLIA. Bíblia de Jerusalém. 4. ed. rev. São Paulo: Paulus, 2006.

BÍBLIA. Tradução Bíblica Ecumênica. São Paulo: Loyola, 1994.

BÍBLIA. Ave Maria: edição de estudos. 3. ed. rev. São Paulo: Paulus, 2012.

BÍBLIA. Novo Testamento: Interlinear. Tradução Waldyr Carvalho Luz. 4. ed. rev. São Paulo: Hagnos, 2010.

CAMPBELL. S. W. Paulo e a criação da identidade Cristã. São Paulo: Loyola, 2011.

CARRANZA, B. Renovação carismática católica, origens, mudanças e tendências. Aparecida: Santuário, 2000.

CARREZ, M. et al. As cartas de Paulo, Tiago, Pedro e Judas. São Paulo: Paulus, 1987.

DUNN, J.D.G. A teologia do Apóstolo Paulo. Tradução Edwino Royer. São Paulo: Paulus, 2003.

HAWTHORNE, G.F.; MARTIN, R.P.; REID, D.G. Dicionário de Paulo e suas cartas. Tradução de Barbara Theoto Lambert. 2. ed. São Paulo: Loyola, 2008.

HUBY, J. História das religiões. Tradução Antonio Pinto de Carvalho, São Paulo: Saraiva, 1963. vol. 3.

LACOSTE, J. Dicionário crítico de Teologia. Tradução Paulo Meneses. São Paulo: Paulinas; Loyola, 2004.

SCHNELLE, U. Paulo Vida e Pensamento. Tradução Monika Ottermann. Santo André: Academia Cristã; São Paulo: Paulus, 2010.

SCIPPA, V. La glossolalia nel Nuovo Testamento: ricerca esegetica secondo il metodo storico-critico e analitico-strutturale. Napoli: D’Auria M, 1982. 
SULLIVAN, F. Carismi e Rinnovamento Carismatico.

Bologna: Ancora, 1983.

VANHOYE, A. I carismi nel Nuevo Testamento. Roma:

Pontifício Instituto Bíblico, 1990.

Recebido em: 01/05/2018

Aceito em: 29/05/2018 